\title{
Türkiye'de Üretilen ve Tüketilen Kuru Kayısılarda Kükürtdioksit Kalıntı Miktarlarının Belirlenmesi
}

\author{
Fatma HEPSAĞ ${ }^{1}$, Ali YILDIRIM² ${ }^{2}$ Özgür GÖLGE ${ }^{1}$, İbrahim HAYOĞLU²* \\ ${ }^{1}$ Gıda Kontrol Laboratuvar Müdürlüğü, Adana \\ ${ }^{2}$ Harran Üniversitesi, Ziraat Fakültesi, Gıda Mühendisliği Bölümü, Şanlıurfa \\ *Sorumlu yazar: ihayoglu@harran.edu.tr
}

Öz

Kuru kayısı, yaş kayısının kurutulmuş şekli olup, ülkemizin geleneksel ihraç ürünleri arasındadır. Ülkemizde kayısı, "Gün Kurusu" ve "Kükürtleme" olmak üzere halen iki metotla kurutulmaktadır. Kuruma süresini kısaltmak, doğal rengi korumak, böceklenmeyi önlemek ve muhafaza süresini artırmak amacıyla yapılan kükürtleyerek kurutma, toplam üretimin \%80'inden fazlasını oluşturmaktadır. Kükürtlemede en önemli sorun kükürt ve nem oranının ayarlanmasıdır. İdeal nem oranı \% $0.2^{\prime}$ dir. Ancak ülkemizde üretilen kayısının şeker oranının yüksek olması nedeniyle nem oranını Avrupa standartlarına indirmek oldukça zordur. Kuru kayısıyı rengini muhafaza ederek 3-4 yıl ve daha uzun süre saklayabilmek için yüksek konsantrasyonda kükürtleme yapılmakta, bu da kayısının tat ve kalitesini olumsuz etkilemektedir. Kükürtlemede daha iyi bir sonuç almak için kullanılan kükürdün kalitesi de yüksek olmalıdır. Kuru kayısı ithal eden ülkelerin izin verdikleri kükürt miktarı; Almanya ve İngiltere'de 2000 ppm (mg kg-1), Fransa ve Danimarka'da 1000 ppm, İtalya'da 600 ppm, Avusturya'da 300 ppm'dir. Ülkemizde ise maksimum limit 2000 ppm'dir. Bu araştırmada; Doğu ve Güneydoğu Anadolu Bölgesindeki market ve pazarlardan tedarik edilen 43 adet kuru kayısıda kükürdioksit analizleri yapılmıştır. Örneklerin 17 adedinde yasal limitlerin (\%40) üzerinde kükürtdioksit bulunmuştur. Bulunan bu sonuçlara göre; üreticiler kükürtleme işlemini daha kontrollü ve modern koşullarda yapmalıdır.

Anahtar kelimeler: Kayısı, Kurutma, Kükürtdioksit

\section{Determination of Sulfurdioxide Residue Levels in Dried Apricots Produced and Consumed in Turkey}

\begin{abstract}
Dried apricot is dried form of fresh apricots and it is one of the traditional export products of Turkey. Apricots are dried with two different methods which are called 'sun dried' and 'sulfurating' in our country. Drying with sulfutaring is applied to shorten the drying time, protect the natural color, prevent infestation and increase storage period and this constitutes more than $80 \%$ of total production. The most important problem in sulfutaring is the adjustment of the sulfur and humidity ratio. Ideal humidity is $0.2 \%$. However, it is very difficult to match the humidity to European standards due to high sugar content of Turkish apricot. Sulfutaring applied in high concentrations which negatively affects taste and quality of the apricots to store the products for 3-4 years or more by keeping colour. The sulfur has to have good quality to get better result in sulfutaring. The amount of sulfur allowed by importer countries of dried apricots are; 2000 ppm (mg kg-1) in United Kingdom and Germany; 1000 ppm in France and Denmark; 600 ppm in Italy and 300 ppm in Austria. The maximum limit is 2000 ppm in Turkey. In this research; sulfurdioxide analysis were performed in total of 43 dried apricot samples collected from markets and bazaars of Eastern and Southeastern Anatolia region. Example of 17 were above the legal limit of sulfurdioxide (40\%). According to these results; sulfutaring has to be applied in more controllable and modern conditions by farmers.
\end{abstract}

Keywords: Apricot, Drying, Sulfurdioxide 


\section{Giriş}

Kayısı TS 791'e göre; Prunus armeniaca L. türüne giren kültür ağaçlarının açık ve koyu sarı renkten turuncu renge kadar çeşitli renk tonlarındaki olgunlaşmış meyvesidir (Anonim, 2010). Kuru kayısı ise, yaş kayısının güneşte veya bilinen diğer metotlardan biri ile kurutulmuş, kükürtlenmiş veya kükürtlenmemiş bir ürün olarak tanımlanmaktadır (Anonim, 2013).

Kuru kayısı, fındık ve kuru üzümden sonra Türkiye'nin en önemli tarımsal ihracat ürünüdür. Bu ürünün en önemli kalite kriteri, karakteristik altın sarısı rengidir. Kuru kayısıların karakteristik renklerinin bozulmasına neden olan en önemli reaksiyon, gerek kurutma gerekse depolama sırasında meydana gelen esmerleşme reaksiyonlarıdır. Esmerleşme reaksiyonları temelde iki şekilde (enzimatik olan ve enzimatik olmayan) gerçekleşmektedir. Kayısılar, kurutma sırasında ve özellikle kurutmanın başlangıcında hızla enzimatik esmerleşmeye uğramaktadırlar. Enzimatik esmerleşme reaksiyonları; açık renkli meyve ve sebzelerin (kayısı, elma, armut, patates vb.) dokularındaki fenolik maddelerin (mono ve o-difenoller vb.), polifenoloksidaz enzimi katalizörlüğünde $o$ kinonlara hidroksilasyonu ve oksidasyonu ile başlamaktadır. Daha sonra, o-kinonların enzimatik olmayan oksidasyonu ve bunu takiben polimerizasyonu sonucunda melanoidinler oluşmakta; böylece bu açık renkli ürünlerde esmerleşme görülmektedir (Cemeroğlu ve Özkan, 2004).

Kayısılarda rengin korunması amacıyla; kükürtleme işlemi yapılmaktadır. Gıda sanayinde kükürt veya sülfit denildiğinde, yandığı veya parçalandığı zaman kükürtdioksit $\left(\mathrm{SO}_{2}\right)$ açığa çıkaran maddeler anlaşılmaktadır. Sülfit formunda kükürt; özellikle laktik asit bakterilerinin, asetik asit bakterilerinin ve küflerin gıdalarda gelişimini önleyen seçici antimikrobiyal bir maddedir. Bütün bu etkilere ek olarak kükürt, sağladığı sayısız avantajları nedeniyle, gıda endüstrisinde kullanımından vazgeçilemeyen bir koruyucu maddedir (Coşkun, 2010).

FAO/WHO Gıda Katkı Maddeleri Ortak Uzmanlar Komitesi kükürtdioksit için günlük alınabilir kabul düzeyini (ADI) günde $0.7 \mathrm{mg} \mathrm{kg}^{-1}$ olarak açıklamışlardır. Buna göre $60 \mathrm{~kg}$ ağırlı̆ı̆ındaki bir birey günlük olarak en fazla $42 \mathrm{mg}$ kükürtdioksidi bünyesine alabilir. Bunun anlamı $2000 \mathrm{mg}$ $\mathrm{kg}^{-1} \quad \mathrm{SO}_{2}$ içeren ortalama 3 kayısının tüketilmesi ile bu değere ulaşılacağıdır. Ancak $2000 \mathrm{mg} \mathrm{kg}^{-1}$ toplam $\mathrm{SO}_{2}$ 'yi ifade etmektedir ve bunun önemli bir kısmının bağlı duruma gelmiş ve sülfata dönüşmüş olduğu düşünüldüğünde $42 \quad \mathrm{mg}^{\prime}$ । karşılayacak kayısı miktarı çok daha fazladır. Kükürdioksit ve sülfit için belirlenmiş $L_{50} 100 \mathrm{mg} \mathrm{kg}^{-1}$ dır. Vücutta serbest sülfit, sülfit oksidaz enzimi ile sülfata yükseltgenip idrar yoluyla kolayca atılmaktadır. Bireylerin kükürdioksit duyarlılığı 3 mg'a kadar düşebilmektedir. 5$50 \mathrm{mg}$ eşiklerinde olan duyarlı hastalar besinlerdeki kükürlü bileşiklere karşı risk gubunu oluşturmaktadır (Bilgiç, 2009).

Ülkemizde halen yaygın olarak uygulanan kükürtleme yöntemine göre; taze kayısılar "islim odası" denilen kapalı odalarda elementer kükürdün yakılmasıyla oluşan kükürtdioksit $\left(\mathrm{SO}_{2}\right)$ gazı atmosferinde tutularak kükürtlenmektedir. Kükürtleme odalarının sızdırmazlığı sağlanamadığı için, hâlihazırda yapılan uygulamalarda; sadece yakılan kükürt 
miktarı ve uygulama süresi kontrol edilebilmektedir. Bu nedenle, kayısıların absorbe ettiği kükürt miktarı çoğu zaman istenilen seviyede olmamakta ve tesadüfe bağlı olarak değişmektedir. Yetersiz seviyede kükürtlemenin getireceği olumsuzluklardan kaçınmak amacıyla; çoğu kez aşırı kükürtleme yoluna gidilmekte, bunun sonucunda ürünün ticari değeri düşmekte ve fazla kükürdün giderilebilmesi için ilave teknolojik işlemlere gereksinim doğmaktadır. Özetle; ülkemizde kuru kayısı üretimindeki temel sorun, kükürtleme işleminin optimize edilememesidir (Coşkun, 2010).

Kuru kayısı üretimi ve ihracatında dünya birincisi olan ülkemizden ithalat yapan başlıca ülkelerin izin verdikleri kükürt miktarı; Almanya ve İngiltere'de 2000 ppm, Fransa ve Danimarka'da 1000 ppm, İtalya'da 600 ppm, Avusturya'da 300 ppm'dir. Ülkemizde ise 30.06.2013 tarihinde Resmi Gazetede yayınlanarak yürürlüğe giren Türk Gıda Kodeksi Katkı Maddeleri Yönetmeliğine göre kuru kayısıda maksimum kükürt miktarı 2000 ppm olarak belirlenmiştir (Anonim, 2015a). Bolat ve Karlıdağ (1999) tarafından Hacıhaliloğlu, Kabaaşı ve Soğancı çeşidi kayısılarda $\mathrm{SO}_{2}$ uygulaması üzerinde çalışıımış olup, $\mathrm{SO}_{2}$ seviyelerinin hasat zamanına bağlı olarak değiştiği ve genel olarak 2000 ppm'in altında olduğu belirlenmiştir.

Bu araştırmada; kuru kayısı ihracatında en önemli sorun olan optimize edilememiş kükürtleme işlemindeki son durumu görmek amacıyla; 2013 yılında Doğu ve Güneydoğu Anadolu Bölgesindeki market ve pazarlardan tedarik edilen 43 adet kuru kayısıda kükürdioksit analizleri yapılmış ve bulunan sonuçların mevzuata uygunluğu değerlendirilmiştir.

\section{Materyal ve Metot}

Kuru kayısı örnekleri 2013 yılında Malatya, Elazığ, Adıyaman ve Şanlıurfa illerindeki market ve pazarlardan tedarik edilmiştir.

\section{$\mathrm{SO}_{2}$ analizi ve miktarının hesaplanması}

30-50 g kayısı örneği ve $230 \mathrm{ml}$ metanol (Sigma) üç yollu balona konuldu ve balonun her iki yandaki muslukları kapatıldı. Deney düzeneğinin üst kısmına yerleştirilen deney tüpünün içine $10 \mathrm{ml} \% 3^{\prime}$ lük hidrojen peroksit (Merck), 3 damla brom fenol (Merck) eklendi. Düzeneğin gerekli bağlantıları yapılarak $15 \mathrm{dk}$ karbondioksit $\left(\mathrm{CO}_{2}\right)$ gazı (Linde) ile ortam doyuruldu. $\mathrm{CO}_{2}$ 'in akış hızı 60 kabarcık/60 saniyede olacak şekilde ayarlandı. Süre bitiminden sonra üç yolu balona; $50 \mathrm{ml}$ saf su (Millipore Elix) ve $40 \mathrm{ml} \% 15$ hidroklorik asit (Merck) eklendi. Düzeneğin soğutma suyu açılarak 60 dakika Sisteme $\mathrm{CO}_{2}$ gazı verilerek kaynatma yapıldı (Anonim, 2013). Süre sonunda sisteme bağlanan deney tüpünde oluşan renkli sıvı; hazırlanan $0.1 \mathrm{~N}$ sodyum hidroksit ile mavi menekşe renge dönene kadar titrasyon yapıldı. Örneklere ait $\mathrm{SO}_{2}$ miktarı aşağıdaki eşitliğe göre hesaplandı (Anonim, 2013).

$\mathrm{SO}_{2}\left(\mathrm{mg} \mathrm{kg}^{-1}\right)=\mathrm{V} \times \mathrm{M} \times 32000 / \mathrm{m}$

V= Kullanılan sodyum hidroksit çözeltisinin miktarı (ml),

$M=$ Kullanılan sodyum hidroksit çözeltisinin derişimi (M),

$\mathrm{m}=$ Numune miktarı $(\mathrm{g})$

\section{Araştırma Bulguları ve Tartışma}

Kuru kayısı örneklerinin kükürtdioksit miktarları Çizelge 1'de gösterilmiştir. Örneklerin 17 adedinde yasal limitlerin (\%40) üzerinde kükürtdioksit bulunmuştur. 
Çizelgeden de görülebileceği gibi; $\mathrm{SO}_{2}$ miktarları 725-2506 mg kg-1 arasında değişmektedir. Kuru kayısılarda $\mathrm{SO} 2$ miktarlarını yayınlayan bir araştırma bulunamadığından; sonuçlar Gıda ve yem için hızlı alarm sistemi (RASFF) bildirimleri ile karşılaştırımış ve sonuçlar paralellik göstermiştir.

Gıda ve yem için hızlı alarm sistemi (RASFF), gıda ve yem zincirinde insan sağlığı ile ilgili riskler saptandığında ve ilgili ürünün alıkonması, geri toplatılması, el konması ve reddedilmesi gibi önlemler alındığında, yetkili otoriteler arasında bilgi değişimini sağlayan hızlı ve etkili bir araçtır. Avrupa Birliği vatandaşları için 1979 yılında kurulmuştur. RASFF bildirim kriterleri 178/2002 Numaralı AB Regülâsyonunun 50. maddesinde verilmiştir. Ne zaman RASSF ağının bir üyesi gıda veya yemden kaynaklanan doğrudan veya dolaylı ciddi bir insan sağlığı riski ile ilgili bir bilgiye sahip olsa, bu bilgi RASFF aracılığıyla hemen Komisyona bildirilir. Komisyon bu bilgiyi hızı bir şekilde ağdaki üyelere aktarır (Anonim, 2015b). Türkiye 2012-2013 RASFF bildirimlerine göre; Avrupa Birliğine ihraç edilen kuru kayısılarda yüksek düzeyde kükürtdioksit bulunmasından dolayı 29 adet geri bildirim almıştır. Bu 29 geri bildirimin 25 adedi $2000 \mathrm{mg} \mathrm{kg}^{-1}$ 'n üzerinde $\quad \mathrm{SO}_{2} \quad\left(2312-2768 \mathrm{mg} \quad \mathrm{kg}^{-1}\right)$ içerdiğinden ihracatına izin verilmemiştir (Anonim, 2015c). Bu durum; kükürt konusunda kurutulmuş ürünleri ithal eden ülkelerin limitlerini karşılama noktasında ülkemiz üreticilerinin yeterince eğitimli ve bilinçli olmadıklarının göstergesidir.

\section{Sonuçlar}

Kuru kayısı üreticilerinin fazla kükürt uygulamasının başlıca iki nedeni vardır: Birincisi; üretici satamadığı kuru kayısının depoda bozulmasını önlemek amacıyla aşırı kükürt kullanmaktadır. İkincisi ise; üretici kısa sürede daha fazla kayısı kükürtlemek için kükürtleme işlemini kerevetler yerine kasalarda yapmaktadır. Yakılan ilk ocakta kasaların ortasında bulunan meyveler yeterince kükürt almadığından ikinci bir kükürtleme daha yapılmaktadır. Böylece kasanın alt ve üst kısımlarında bulunan kayısılar aşırı miktarda kükürt absorbe etmektedir.

Bu probleme çözüm olarak; çiftçinin kısa sürede pazarlayacağı kayısıya 2000 ppm, depoda uzun süre bekleteceği kayısıya 3.000-3.500 ppm kükürt uygulaması ve kükürtlemenin mutlaka kerevetlerde yapılması, optimum kurutma tekniklerinin tespit edilmesi, geleneksel kükürtleme odalarını modern hale getirme imkanlarının araştırılması önerilebilir.

\section{Kaynaklar}

Anonim, 2010. Kayısı Standardı (TS 791), Türk Standartları Enstitüsü, Ankara.

Anonim, 2013. Kuru Kayısı Standardı (TS 485), Türk Standartları Enstitüsü, Ankara.

Anonim,

$2015 a$.

http://www.resmigazete.gov.tr/eskil er/2013/06/20130630-4.htm._Erişim: 28.04.2015.

Anonim,

2015b. http://www.europeanlawmonitor.or g/News/Latest-EU-News/Questionsand-Answers-on-the-Rapid-AlertSystem-for-Food-and-FeedRASFF.html. Erişim: 28.04.2015. Anonim,

2015c. https://webgate.ec.europa.eu//rasff -window/portal/\#. Erişim: 30.04.2015.

Bilgiç, Y., 2009. Farklı Meyve Çeşidi ve İriliğine Sahip Kükürtlenmiş Kayısı 
Kurularında $\mathrm{H}_{2} \mathrm{O}_{2}$ Uygulamasının $\mathrm{SO}_{2}$ Kükürt Kalıntısına Etkisi, Yüksek Lisans Tezi, Selçuk Üniversitesi Fen Bilimleri Enstitüsü, Konya.

Bolat, i., Karlıdağ, H., 1999. The Effects of Harvest Periods on $\mathrm{SO}_{2}$ Content and Fruit Quality of Turkish Dried Apricot. ACTA Horticulturae, 488: 615-618.

Cemeroğlu, B., Özkan, M., 2004. Kurutma Teknolojisi. "Alınmıştır: Meyve ve
Sebze İşleme Teknolojisi. (Ed) Cemeroğlu, B., Başkent Klişe Matbaacılık, Ankara, Türkiye, s479618.

Coşkun, A.L., 2010. Farklı Kükürtleme Yöntemlerinin ve Depolama Sıcaklıklarının Kuru Kayısıların Fiziksel ve Kimyasal Niteliklerine Etkisi, Doktora Tezi, Ankara Üniversitesi Fen Bilimleri Enstitüsü, Ankara.

Çizelge 1. Kuru kayısı örneklerinin $\mathrm{SO}_{2}$ miktarları

Table 1. $\mathrm{SO}_{2}$ contents of dried apricot samples

\begin{tabular}{|c|c|c|c|c|c|}
\hline $\begin{array}{l}\text { Örnek } \\
\text { Sample }\end{array}$ & $\begin{array}{l}\mathrm{SO}_{2} \text { miktarı }\left(\mathrm{mg} \mathrm{kg}^{-1}\right) \\
\mathrm{SO}_{2} \text { content }\left(\mathrm{mg} \mathrm{kg}^{-1}\right)\end{array}$ & $\begin{array}{l}\text { Örnek } \\
\text { Sample }\end{array}$ & $\begin{array}{l}\mathrm{SO}_{2} \text { miktarı }\left(\mathrm{mg} \mathrm{kg}^{-1}\right) \\
\mathrm{SO}_{2} \text { content }\left(\mathrm{mg} \mathrm{kg}^{-1}\right)\end{array}$ & $\begin{array}{l}\text { Örnek } \\
\text { Sample }\end{array}$ & $\begin{array}{l}\mathrm{SO}_{2} \text { miktarı }\left(\mathrm{mg} \mathrm{kg}^{-1}\right) \\
\mathrm{SO}_{2} \text { content }\left(\mathrm{mg} \mathrm{kg}^{-1}\right)\end{array}$ \\
\hline 1 & 2476 & 16 & 2302 & 31 & 2135 \\
\hline 2 & 2200 & 17 & 1260 & 32 & 1629 \\
\hline 3 & 885 & 18 & 2621 & 33 & 1225 \\
\hline 4 & 2284 & 19 & 2337 & 34 & 1875 \\
\hline 5 & 562 & 20 & 2304 & 35 & 2402 \\
\hline 6 & 1813 & 21 & 2505 & 36 & 2301 \\
\hline 7 & 725 & 22 & 1910 & 37 & 2132 \\
\hline 8 & 931 & 23 & 1272 & 38 & 956 \\
\hline 9 & 854 & 24 & 1125 & 39 & 874 \\
\hline 10 & 1116 & 25 & 725 & 40 & 1042 \\
\hline 11 & 1380 & 26 & 1208 & 41 & 1785 \\
\hline 12 & 2302 & 27 & 884 & 42 & 2506 \\
\hline 13 & 1921 & 28 & 731 & 43 & 2401 \\
\hline 14 & 2805 & 29 & 2449 & & \\
\hline 15 & 1176 & 30 & 1955 & & \\
\hline \multicolumn{2}{|c|}{ Minimum (Min.) } & & & & 725 \\
\hline \multicolumn{2}{|c|}{ Maksimum (Max.) } & & & & 2506 \\
\hline \multicolumn{2}{|c|}{ Ortalama (Average) } & & & & 1680.95 \\
\hline
\end{tabular}

